1. BDS, FCPS

Assistant Professor

Oral \& Maxillofacial Surgery

Department

Faculty of Dentistry LUMHS, Jamshoro

2. BDS, FCPS

Assistant Professor

Oral \& Maxillofacial Surgery

Department

Faculty of Dentistry LUMHS,

Jamshoro

3. BDS, MSc

Assistant Professor

Community Dentistry Department Faculty of Dentistry LUMHS,

Jamshoro

4. BDS, MSc (Trainee)

Oral \& Maxillofacial Surgery

Department

Faculty of Dentistry LUMHS,

Jamshoro

5. MBBS, FRCS

Associate Professor

General Surgery Department

LUMHS, Jamshoro

Correspondence Address:

Dr. Suneel Kumar Punjabi

Assistant Professor

Oral \& Maxillofacial Surgery

Department

Faculty of Dentistry LUMHS, Jamshoro

drsunilpanjabi@yahoo.com

Article received on:

13/05/2015

Accepted for publication:

22/03/2016

Received after proof reading:

04/05/2016

\section{ISOLATED ZYGOMATIC BONE FRACTURE; MANAGEMENT BY THREE POINT FIXATION}

\author{
Dr. Suneel Kumar Punjabi', Dr. Kashif Ali Channar², Dr. Munir Ahmed Banglani ${ }^{3}$, Dr. Naresh Kumar ${ }^{4}$, \\ Dr. Ambreen Munir ${ }^{5}$
}

ABSTRACT... Introduction: Facial bones injuries results in functional disturbances. Patients may presents with flattening of normal malar prominence, lid drop, eye movement limited or with double vision, numbness of cheek area and unilateral epitasis. Emphasizing upon incision type, fixation method and occasionally reconstruction, surgeons suggest different methods for repairing complex fractures of Zygoma. Study Design: Descriptive study. Setting: Department of Oral \& Maxillofacial Surgery, Liaquat University of Medical \& Health Sciences, Jamshoro. Period: Mar 2013 to Feb 2014. Materials and methods: Total 20 patients were included. Patients with fracture more than 28 days old were excluded. Zygomatic bone can be approached by lateral brow or subcilicary incisions and by subgingival buccal sulcus approach. When 3 fracture sites were reduced and aligned satisfactorily, application of miniplates was performed at 3 points frontozygomatic suture, Zygomatico maxillary buttress and infraorbital rim, wound were closed in 2 layers. At $2^{\text {nd }}$ week follow-up patients were assessed for outcome. Results: There were 14 male and 6 female patients. Most were of age $<25$ years. $45 \%$ fractures were due to RTA. Duration of fracture of 2 patients was 2 days, 7 days of 11 patients, 4 patients had 14 days and 3 patients had 28 days. 5 fractures were reduced using Gilies temporal approach, 6 with Keen approach, 4 with Hook approach and 5 with Dingman approach. Preoperatively, 17 patients had facial asymmetry, 19 had limited mouth opening and postoperatively this was reduced to 6 cases each for facial asymmetry and limited mouth opening. Conclusion: It is concluded from this study that three point fixation is most effective and safe method for reduction of fracture of Zygomatic bone.

Key words: Facial bones, Zygomatic bone fracture, Endopthalmous

Article Citation: Punjabi SK, Channar KA, Banglani MA, Kumar N, Munir A. Isolated zygomatic bone fracture; Management by three point fixation. Professional Med J 2016;23(5):526-530. DOI: 10.17957/TPMJ/16.2934

\section{INTRODUCTION}

Facial bones are one of the most important and complex portion of skeletal anatomy. Injuries to them result in devastating emotional as well as functional disturbances. Cranium and maxilla are buttressed mainly by Zygomatic bone. It's convex shaped thus more vulnerable to fracture. If the zygomatic fracture is not placed appropriately it may cause the malar to be flattened significantly, ocular dystopia and enophthalmos. ${ }^{1}$

Zygomatic fractures are reported to be the second most frequent fracture among the facial bones with considerably high male to female ratio (4:1), which ranges from 3-5:1 (developed world) up to 10-40:1 (developing world). ${ }^{2,3}$ The two most common causes of complex fractures of zygoma are reported to be RTA and assaults (31\%). ${ }^{4}$

Patients with fracture of the Zygomatic bone may presents with flattening of normal malar prominence, lid drop, eye movement limited or with double vision, numbness of cheek area and unilateral epitasis. Disrupted zygoma not only cause impaired ocular and mandibular functions but it also affects the aesthetic and psychology of the patient. Thus, the appropriate diagnosis and adequate management are essential to achieve aesthetic and functional results. ${ }^{4}$

As with any fracture proper diagnosis is mandatory so diagnosis of isolated Zygomatic fracture can be made by clinical and radiographical examination. 
Diagnosis and reconstruction of zygomatic complex fractures may become a challenge to a surgeon..$^{5,6}$ Emphasizing upon incision type, fixation method and occasionally reconstruction, surgeons suggest different methods for repairing complex fractures of Zygoma. Dingman's approach is more popular among others including Keen's, Gillies' and bicoronal scalp flap approaches for open reduction with surgical incision. However, performing Gillies' temporal approach is simpler with best aesthetic results, hence commonly practiced in UK. ${ }^{7,8}$ For good functional stability and esthetics the Isolated Zygomatic bone fracture are correctly reduce and fix with three point fixation, however some other researcher suggest that two point fixation is sufficient to maintain the good functional esthetical result.

This study was carried out to find out whether 3 point fixation gives better treatment option for isolated zygomatic bone fracture in terms of achieving stable fixation with minimized morbidity.

\section{MATERIALS AND METHODS}

This descriptive study was done at Department of Oral \& Maxillofacial Surgery, Liaquat University of Medical \& Health Sciences, Jamshoro from Mar 2013 to Feb 2014.

After the approval of local ethics committee of the university, trial was approved and registered at Research, Training and Monitoring Cell of the university under enrolment No.PG/2131, 2011.

After obtaining the written informed consent 20 patients 10 women and 10 men aged 1830 years were included in this study. Patients meeting inclusion criteria were Displaced Isolated Zygomatic Bone fractures conformed on clinically \& radiologically features (Occipito-mental view $15^{\circ}$, Sub-Mento-Vertex View or Caldwell's posterior-anterior view), patients with zygomatic bone fracture displaced in other directions but more than 15 days old and Patients willing to participate in study. Patients who had gunshot injuries and comminuted fractures of zygomatic bone, Bilateral displaced fractures of zygomatic bone, associated injuries which are likely to delay early open reduction internal fixation of the zygomatic complex, Patients with old, malunited, untreated fractures time passed more than 15 days without treatment and patients who were medically unfit for surgery or to undergo general anesthesia were excluded from the study.

Function (mouth opening, diplopia, vertical dystopia and enophthalmos) and esthetic (malar prominence) problems were identified preoperatively. Operative management of these patients includes open reduction and non compression mini plates. All patients were operated under general anesthesia; exposure of zygomatic bone was achieved with lateral brow incision and subcilicary incision. After ensuring reduction and satisfactory aligment at 2 fracture sites, mini plates were applied at 2 points frontozygomatic suture and infraorbital rim, wound were closed in 2 layers after through irrigation, patients were kept on follow up on first two weeks. At the time of $2^{\text {nd }}$ week follow-up patients were assess the following parameters and recorded (Annex \# 1).

\section{CLINICAL FUNCTIONAL ASSESSMENT}

\section{Vertical dystopia}

It was measure using photograph of the patient holding a centimeter ruler vertically within the same field. Level of the horizontal mid-pupillary line was recorded for each side to find out the discrepancy

\section{Aesthetic: (photographic) assessment}

Frontal and basal views of the patients at first week of follow-up were taken and were assess for malar depression by an experienced independent clinical investigator. Malar asymmetry of the patients was graded as per Holmes and Mathew's classification system.

Grade I: Excellent cosmetic result, no malar asymmetry

Grade II: Good cosmetic result, malar asymmetry on careful inspection

Grade III: Poor cosmetic result, noticeable malar 
asymmetry

Grade IV: Gross malar asymmetry.

\section{Radiological assessment}

At the first Postoperative week radiograph were taken for the assessment of reduction and fixation of Isolated Zygomatic Bone Fracture:

1-Occipito-mental View $15^{\circ}$.

2-Sub-Mento-Vertex View.

\section{RESULTS}

Among 20 study subjects, 14(70\%) patients were male and $6(30 \%)$ patients were female. The age distribution showed that, $11(55 \%)$ patients were $<25$ years and $9(45 \%)$ patients were $\geq 25$ years of age. The etiology of fracture showed that 9 fractures were due to RTA, 8 due to assault and 3 due to fall. Right zygomatic bone was involved in 12 cases and left zygomatic bone was involved in 8 cases. The frequency distribution is presented in Table-I.

Results regarding duration of fracture showed that $10 \%$ patients had duration of 2 days, $55 \%$ patients had duration of 7 days, $20 \%$ patients had reported duration of 14 days and $15 \%$ patients were reported duration of 1 month. Frequencies are presented in Fig-1. The result regarding reduction in fracture showed that 5(25\%) fractures was reduced using Gilles temporal approach, 6(30\%) with Keen approach, 4(20\%) with Hook approach and $5(25 \%)$ was reduced using Dingman approach also presented in Fig2. The frequency distribution and association is presented in Table-II.

Pre and post operative findings were also compared. Pre operatively, $85 \%$ patients had facial asymmetry, 95\% also had limited mouth opening, $20 \%$ had diplopia, and $15 \%$ had Endopthalmous. Postoperative findings showed reduction in fracture. $30 \%$ of cases had facial asymmetry, 30\% had limited mouth opening, 5\% had diplopia, and No had Endopthalmous (Fig$3)$. The frequency distribution and association is presented in Table-III.

$$
\text { Frequency (n) } \quad \text { \%age }
$$

\begin{tabular}{|l|l|c|c|}
\hline \multirow{2}{*}{ Gender } & Male & 14 & $70 \%$ \\
\cline { 2 - 4 } & Female & 6 & $30 \%$ \\
\hline \multirow{2}{*}{ Age } & $<25$ years & 11 & $55 \%$ \\
\hline \multirow{3}{*}{ Etiology } & $\geq 25$ years & 9 & $45 \%$ \\
\hline \multirow{3}{*}{ Side } & RTA & 9 & $45 \%$ \\
\hline \multirow{2}{*}{} & Assault & 8 & $40 \%$ \\
\cline { 2 - 4 } & Fall & 3 & $15 \%$ \\
\hline \multirow{2}{*}{} & Right Bone & 12 & $60 \%$ \\
\cline { 2 - 4 } & Left Bone & 8 & $40 \%$ \\
\hline
\end{tabular}

Table-I. Frequency Distribution of Patients According to Gender and Age

\begin{tabular}{|c|c|c|c|}
\hline & & Frequency (n) & \%age \\
\hline \multirow{4}{*}{$\begin{array}{l}\text { Duration } \\
\text { of Fracture }\end{array}$} & 2 days & 2 & $10 \%$ \\
\hline & 7 days & 11 & $55 \%$ \\
\hline & 14 days & 4 & $20 \%$ \\
\hline & 1 month & 3 & $15 \%$ \\
\hline \multirow{4}{*}{$\begin{array}{l}\text { Treatment } \\
\text { Approach }\end{array}$} & $\begin{array}{l}\text { Gilies Temporal } \\
\text { approach }\end{array}$ & 5 & $25 \%$ \\
\hline & Keen approach & 6 & $30 \%$ \\
\hline & Hook approach & 4 & $20 \%$ \\
\hline & $\begin{array}{l}\text { Dingman } \\
\text { approach }\end{array}$ & 5 & $25 \%$ \\
\hline
\end{tabular}

Table-II. Frequency Distribution of Patients According to Duration of Fracture and Treatment Approach

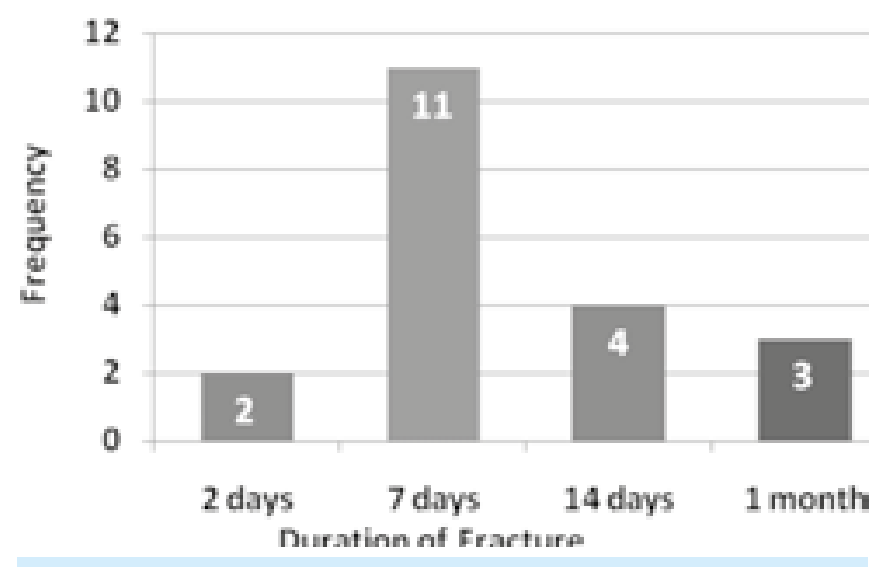

Fig-1. Frequency of Duration of Fracture 


\begin{tabular}{|c|c|c|c|c|}
\hline & \multicolumn{2}{|c|}{ Pre Operative } & \multicolumn{2}{|c|}{ Post Operative } \\
\hline & Frequency (n) & \%age & Frequency (n) & \%age \\
\hline Facial Asymmetry & 17 & $85 \%$ & 6 & $30 \%$ \\
\hline Limited Mouth Opening & 19 & $95 \%$ & 6 & $30 \%$ \\
\hline Diplopia & 4 & $20 \%$ & 1 & $5 \%$ \\
\hline Endopthalmous. & 3 & $15 \%$ & -- & $\%$ \\
\hline
\end{tabular}

Table-III. Frequency Distribution of Patients According to Duration of Fracture and Treatment Approach

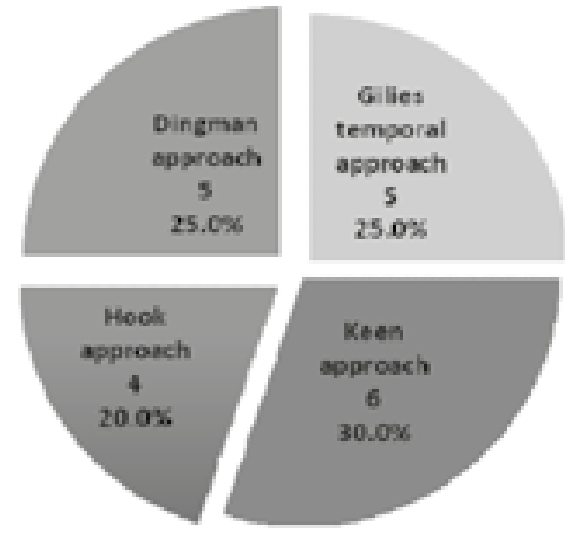

Fig-2. Percentage of Duration of Fracture

\section{DISCUSSION}

Fracture of zygomatic bone leads to facial disfigurement as well as difficulty in opening mouth. There are many surgical options / approaches for the reduction of fracture. These include Gillies temporal approach, Dingman approach and Keen Approach. The simple approach for the stability of reduction is open reduction and internal fixation. In a study, it was reported that the three point fixation was using either wiring or miniplates resulting in great stability. Three point fixation is better based on inadequate results from two point fixation approach.

In this study we hypothesize that three point fixation has better clinical results and benefits to the patients.

The distributions of gender this study had similar gender distributions that had been reported by a study where majority of patients were males. Male preponderance is due to vulnerability to road traffic accidents and assaults. Also, in our society male are more participating in sports compared to female which is again exposing

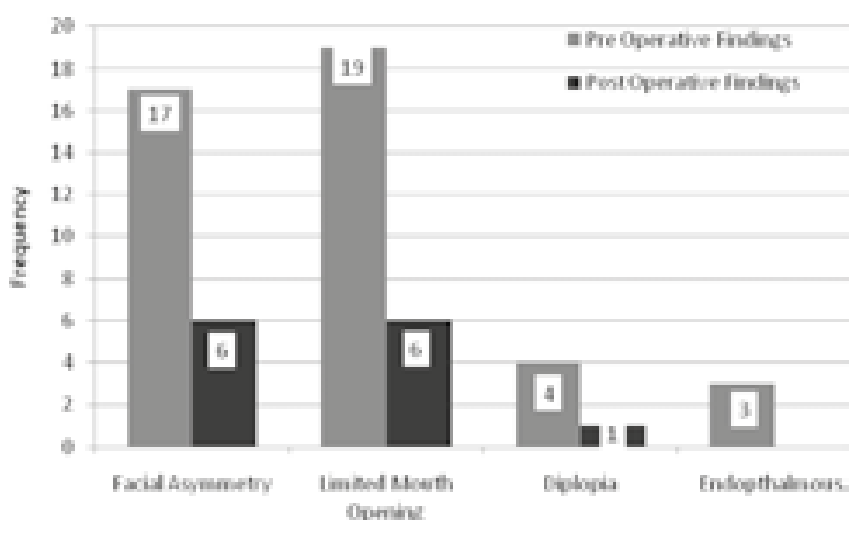

Fig-3. Comparison of Pre and Post Operative Findings

male for the fracture. Most other studies reported higher male to female ratio. ${ }^{9}$ The average male to female ration from developed countries ranging from 3-5:1. The average male to female ratio in developing countries this ratio was 10-40:1.

In this study, the most common etiology of zygomatic bone fracture was road traffic accident followed by assault and fall. This finding was also reported by other studies as well.

In this study we found the fracture of right side of zygomatic bone is common. The most common approach for reduction of fracture was Keens approach accounting followed by Hook, Gilies approach and Dingman approach. Other studies also reported the above mentioned reduction approaches for the reduction of the zygomatic bone fracture.

In this study, the most common preoperative finding was facial asymmetry and limited mouth opening with $90 \%$ each followed by diplopia and Endopthalmous. Postoperative, this findings was reduced to $30 \%$ of cases had facial asymmetry and limited mouth opening each followed by $5 \%$ 
diplopia and none had Enophthalmous. Hence it was concluded that three point fixation is more effective in the stability of reduction of zygomatic bone fracture.

\section{CONCLUSION}

It is concluded from this study that three point fixation is most effective and safe method for reduction of fracture of zygomatic bone.

Copyright@ 22 March, 2016.

\section{REFERENCS}

1. Parashar A, Sharma RK. Management of zygomatic fractures. Ann Plastic Surg. 2013;70(6):742.

2. Chowdhury SKR, Menon PS. Etiology and management of zygomatico-maxillary complex fractures in the armed forces. Med J Armed Forc Ind. 2005;61:238-40.

3. Tadj A, Kimble FW. Fractured zygoma. Aus New Zea J Surg. 2003;73:49-54.
4. Nayyar MS. Management of zygomatic complex fracture. J Coll Physicians Surg Pak. 2002;12:700-05.

5. Matsunaga RS, Simpson W, Toffel PH. Simplified protocol for the treatment of malar fractures. Based on a 1,220-case, eight-year experience. Arch Otolaryngol. 1977;103:535-38.

6. Evans BG, Evans GR. Zygomatic fractures. Plast Reconstr Surg. 2008;121:1-11.

7. Lee PK, Lee JH, Choi YS. Single transconjunctival incision and two-point fixation for the treatment of noncomminuted zygomatic complex fracture. $\mathrm{J}$ Korean Med Sci. 2006, 21:1080-85.

8. Courtney DJ. Upper buccal sulcus approach to management of fractures of the zygomatic complex: a retrospective study of 59 cases. Br J Oral Maxillofac Surg. 1999;37:464-68.

9. Punjabi SK, Habib-ur-Rehman, AZ, Ahmed S. Causes and management of zygomatic bone fractures at Abbasi Shaheed Hospital Karachi (analysis of $\mathbf{8 2}$ patients). J Pak Med Assoc. 2011;61:36-9.
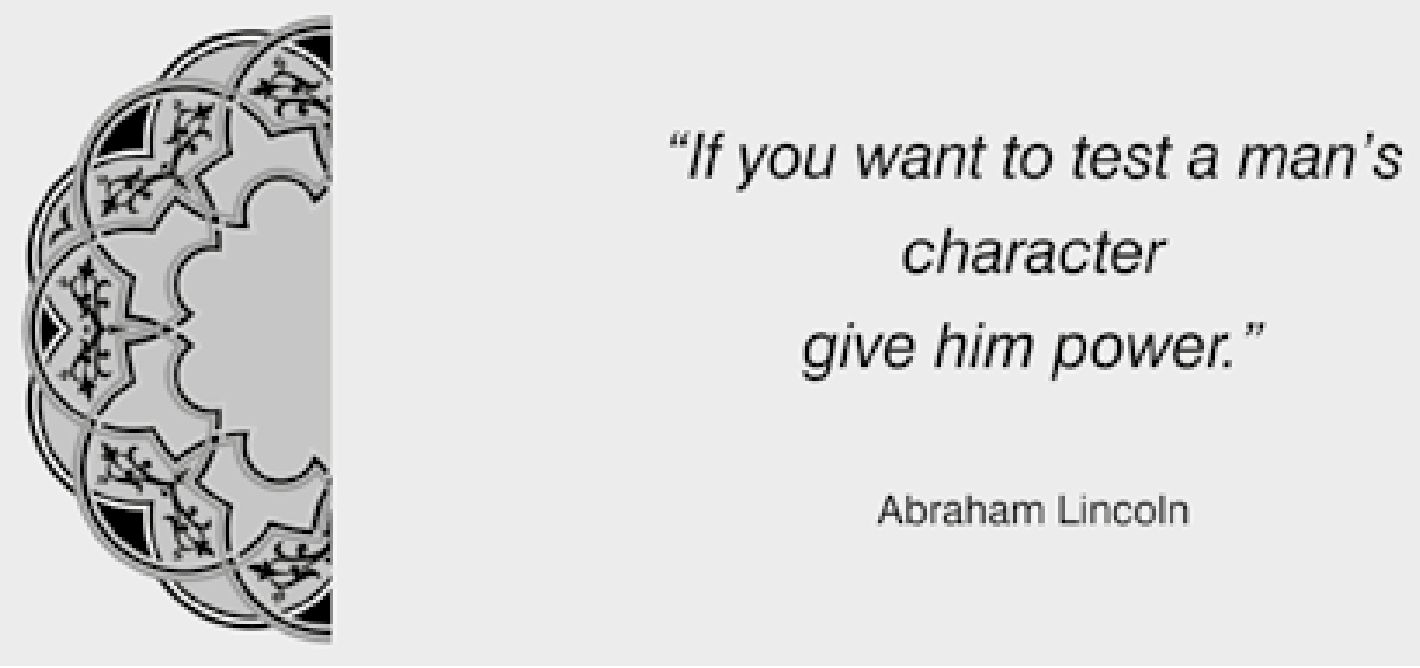

Abraham Lincoln

\section{AUTHORSHIP AND CONTRIBUTION DECLARATION}

\begin{tabular}{|c|l|}
\hline Sr. \# & \multicolumn{1}{|c|}{ Author-s Full Name } \\
\hline 1 & Dr. Suneel Kumar Punjabi \\
2 & Dr. Kashif Ali Channar \\
3 & Dr. Munir Ahmed Banglani \\
4 & Dr. Naresh Kumar \\
5 & Dr. Ambreen Munir \\
\hline
\end{tabular}

Contribution to the paper

Concept, Methodology \&

Study Design

Data collection \& Intro

writing

Discussion, References

Data collection \& results

Abstract writing \& review
Author $=\mathbf{s}$ Signature

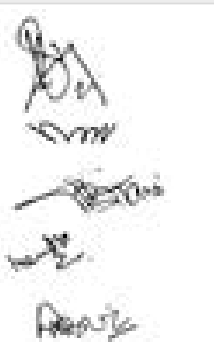

